\title{
“Steve, you must feel pig sick!”: Streamed Video Interactions between Premier League Managers and Sports Journalists as Semi-scripted Per- formances
}

\begin{abstract}
The starting point of this paper is the phenomenon of so-called MediaSport, namely the pervasive and multi-faceted mediation of sports events that extends the reach and hold of the sports industry on communities of sports consumers. The specific aspect of MediaSport considered here is the streamed post-match interview with Premier League team managers, a stabilized media interaction that reflects the importance of media duties as part of the manager's corporate brief. Critical attention to managers seems mainly confined to sociological studies of the politics of celebrity, while linguists seemingly have little to say about this kind of discourse. The data selected for analysis are two interviews following defeat. The choice falls on this scenario because it is expected it will entail a greater onus on managers to display media interaction expertise. Using a theoretical framework that draws on Goffman's concepts of performance, participation framework, and face, the discourse analysis in this paper attempts to provide an account of the linguistic resources managers draw on in these mediated interactions. The analysis of turn-taking, topic control, deixis and modality reveals similarities in the sample interviews that suggest these encounters are actually semi-scripted collaborative performances that allow both interactants to preserve their face as competent professionals, while also affording the manager ample opportunity to interact with the major imagined recipient, namely, the online fan base.
\end{abstract}

\section{Introduction}

The focus of this article is the impact of developments in Information Communication Technology on the corporate reality of Premier League football clubs, as represented through their managers during streamed post-match interviews. These media events, especially if they are subsequent to defeat, appear to revolve round issues of personal and enterprise image, if not face. The focus of the article is on discourse, primarily considering the linguistic strategies and media skills managers have developed to perform effectively in this increasingly widespread and accessed genre of what Wenner describes as MediaSport (1998).

\subsection{Structure of the article}

The following article is divided into a further nine sections. Section 2 defines the phenomenon of MediaSport and outlines how it extends the corporate reach of clubs by creating consumption communities (Fairclough 1989: 166) that transcend local and national boundaries. Section 3 defines the media genre of the post-match streamed interview and presents it as a recent example of the commodification of sports information for such cultural groups. Section 4 considers the emergence of the football manager as a celebrity and the nature of his relations with the media. Section 5 outlines the theoretical framework for the close linguistic analysis of such discourse. The framework is comprised of three interlocking concepts elaborated by Goffman $(1959,1981,1967)$ : performance, participation framework, and face. Section 6 presents the data selection criteria and explains its relevance to the analytical framework as a whole. Section 7 considers two such media interactions from the point of view of performance. The linguistic analysis in this section focuses

\footnotetext{
* Dermot Heaney

Dipartimento di studi filologici, linguistici e letterari

Facoltà di Lettere e Filosofia

Università 'Tor Vergata'

Rome, Italy

heaney@lettere.uniroma2.it
} 
particularly on the turn-taking system and topic control. Section 8 focuses on the participation framework, particularly on the role of the ratified overhearing audience, in all probability comprised largely of the team's cyber fan base. The linguistic analysis in this section centres on the role of deixis in establishing identities and relations within the participation framework. Section 9 analyses the sample interviews in the light of Goffman's concept of face and Bordieu's concept of habitus (cited in Watts 2003). The discourse analysis in this section concentrates on the linguistic resources that the main participants draw on to perform facework, with particular reference to modality and the turn-taking system. Section 10 is the conclusion. On the basis of the data analysed, this section attempts to provide a summary of the minimally nuanced account of the linguistic resourcefulness of managers interviewed following defeat. It also attempts to link these resources to the performance aspects of a media genre that ultimately appears to allow managers scope for liaising with the ratified overhearing audience of the fan base and for actuating face maintenance strategies. In the final part of the conclusion, it is suggested that losing managers tend to subsume defeat into the semantics of uncertainty, which is seen as one of the sustaining attractions of all sports. In doing so, they are conceivably underlining an overarching reason for continued consumption of the team brand, despite the temporary 'disservice' of defeat.

\section{Football as MediaSport}

In the preface to the Deloitte Annual Review of Football Finance 2009, Jones (2009: 2) paints a glowing picture of an industry where between 1992 and 2008 all England's major football leagues achieved 'stratospheric' growth rates that dramatically outpaced an average economic growth of $5.4 \%$ in the UK for the same period. What is more, the Deloitte Annual Review (2009: 3) also stresses that football continues to attract fans to matches, despite the generalized economic downturn. However, football clubs do not flourish by filling stadia alone. Broadcasting deals have become increasingly important for the survival of many of them and for the future health of the sector. This growing symbiosis with broadcasting media has seen football mutate from a game into possibly the most virulent of what Wenner (1998: xiii) calls "a new genetic strain called MediaSport", the result of "the cultural fusing of sport with communication". In the view of Real (1998: 14), the huge scale of the MediaSport phenomenon "is there in the explosion of sport talk radio, sport magazines, Internet sport sites, and consequent global sport marketing”.

\subsection{MediaSport and the creation of consumption communities}

MediaSport analysts focus on three main ways in which it drives the sports industry. Whitsun (1998: 52), for example, stresses MediaSport's economic potential to further extend "the construction of communities of sporting interest" because "the boundaries between what used to be related but separate activities - the promotion of sports and the use of sports events and personalities to promote other products - are also being dissolved". Another area of analysis is the sociocultural implications of audience participation. Beard (1998: 6), for instance, describes a situation in which, for many poorer fans, "identity with the club is far more likely to come from wearing its merchandise than from going to games". A further focus is on the psychological effects of MediaSport and their commercial repercussions. Bellamy (1989: 242) includes affective involvement as a significant motivation for viewing sports on television, describing how fans who "often seek identification with players or teams, vicariously share in competition, and may 'fantasize' competing". This situation would appear to fulfil the need for what Fairclough (1989: 166) calls "ersatz communities", which for social and psychological reasons, "provide people with needs and values” As Fairclough (1989: 166) points out, "these groups have been called consumption communities". There can be few more closely knit examples of such cultural communities than a football club's national and international fan base. Real (1998: 14) spells out the financial gains to be made by exploiting this hold on the MediaSports fan, "who modifies clothing and decoration [...] and in other psychological and visible ways expresses the central importance that mediated sports occupy in individual lives”. In his analysis of Jose Mourinho's rise to fame and influence, Wagg 
(2007: 448) describes how the media and cult of the football manager combine to secure corporate aims by creating an international consumption society that he also refers to as a "cyber-tribe":

\begin{abstract}
He [Jose Mourinho] has, via the global media outlets of television and the Internet, become the focal point of the ongoing campaign to make Chelsea a world brand - to persuade people to think of Chelsea as 'we'. This has entailed, as so often in football fandom, the promotion of a particularism [...] This particularism will in the main be carried by a global cyber-tribe, adopting the club's apparel, watching them on TV in bars and cafes across the world and communing with other converts on the internet.
\end{abstract}

\title{
3. The commodification of sport and technology
}

In addressing the issue of the commodification of sports, Real (1998: 14) notes how the committed MediaSport fan "searches out supplemental sources of information" about the sport of his or her choice. The last two decades have witnessed an exponential increase in opportunities for unimpeded consumption of mediated sports information. As Real (2006: 171) points out, "from its explosion in the last decade of the twentieth century, the World Wide Web has become an ideal medium for the dedicated sports fanatic". Mahan/McDaniel (2006: 412) note that "one of the unique aspects of online sport [...] is that it allows a sporting brand [...] to maintain a constant global media presence" and "promotional platform for its corporate sponsors [...]".

Streaming is a further radical supplement to traditional broadcasting outlets because it has extended the reach and duration of sports' media presence. Formerly, there was relatively limited access to post-match interviews. They were normally inserted at the end of the recorded highlights of matches featured on weekly football roundup programmes like the BBC's Match of the Day. This meant that they were limited in number and frequency.

Post-match interviews still normally begin their digital life as part of live televised coverage of a match, or as part of the highlights that include contributions from various managers, and they continue to be broadcast as a regular feature of football roundup programmes. However, the Web ensures that they now have a much longer shelf life. A typical example is provided by the BBC, which uses these interviews both for conventional broadcasts and then embeds them as part of the multimodal coverage on the football pages of its website. It is routine for two interviews to be included per match report. Subsequently the interviews may be stored as links on the audio and video pages devoted to each club, remaining available for viewing for some time after the match. Eventually many of these interviews will continue their online life in video sharing networks like Youtube.com.

This process is a radical extension of Beard's (1998: 64) analysis of football as a mediated sport, in which "the whole package gives an entertainment which goes well beyond the game itself". The post-match interview is one of the aspects of the game that has been developed to systematically protract it. Official club websites themselves have woken up quickly to the potential of such mediated interactions as commodities. A recent feature of many Premier League club official sites is an archive of press conferences and interviews with managers, which fans can access by payment of an annual subscription. Subscribers not only pay for their subscriptions, they also consume the sponsor logos and team merchandise that feature as props in the conventionalized interview settings. Moreover, in a recent development, the post-match interview is routinely preceded by a free-standing advertisement. This situation confirms Wilkinson's (2006: 134) view that "sport is another realm of synergy where old and new have converged, creating new behaviors and lifestyles for consumers".

\section{Managers as celebrities}

Football has attracted considerable interest from both social historians, interested in the sport as an index of social change over time, and from sociologists, who have investigated it extensively from the point of view of identity (Smith/Porter 2004), gender (Wagg 2004), race (Giulianotti 1999), and politics (Beck 1999; Armstrong/Mitchell 2008). In a recent streamed mini-documen- 
tary series, embedded in the multimedia section of the online version of The Guardian, senior sports writer Barney Ronay (2009) refers to football managers as "the most important men in the most important sport”. Following the rise of certain high profile managers like Jose Mourinho and Sven-Goran Eriksson, academics have also begun to investigate football management from the point of view of the politics of celebrity (Wagg 2007). Whitsun (1998: 62) defines a sports star as "someone whose name and fame have been built up to the point where reference to them [...] can serve as a professional booster in itself". Beard (1998: 65) is of the opinion that what is said in post-match interviews is not the real issue, "rather the fact that [...] the stars [can be] seen in close-up, is often justification enough". The unwavering media attention managers are now exposed to means that they are increasingly seen as celebrities. As such, they are expected to talk regularly to the media.

\subsection{Managers as communicators}

Traditionally, managers were not known for their communication skills or expected to be effective communicators. Sports journalist Ken Jones (1996) makes the point that managers are not trained to be experts in communication. He quotes a prominent football manager who confesses that "of all the things expected of me, I find speaking to the media immediately after matches, the most difficult" (cited in Beard 1998: 65). According to Jones (1996), one particular difficulty managers have in speaking after matches is that of suppressing their innermost feelings. More than ten years have passed since that comment was made, and the media exposure that now goes with the job has become even more unrelenting, partly as a consequence of streaming, which has extended the accessibility and the shelf life of such interactions, and therefore the ability of various audiences to scrutinise managers' interview performances. Managers are presumably aware of this development.

The post-match interview is usually a contractual obligation for managers. Beard (1998: 65) stresses that "in many sports players and officials are obliged by contract to give interviews after an event", and he suggests that one important way of coping with the pressure of these post-match interviews "can be to continue talking" (1998: 65). The main purpose of this article is to delineate the ways in which managers continue talking, and to define what Beard (1998: 67) calls coping strategies. A further aim is to consider whom managers are addressing and to what extent their interviews are shaped by awareness of the overhearing "cyber-tribe".

\section{The theoretical framework}

The theoretical framework for the ensuing media discourse analysis is provided by three interrelated and overlapping concepts developed by Goffman $(1959,1981,1967)$ each of which seems particularly relevant to the media interaction of the post-match interview: performance, participation framework and face.

\subsection{Performance: dramaturgical aspects}

Goffman (1959: 26) conceives the way in which the individual presents himself and his activity to others as a performance, which he describes as "all the activity of a given participant on a given occasion which serves to influence in any way any of the other participants". He (1959: 27) further refines this as follows: "the pre-established pattern of action which is unfolded during a performance and which may be presented or played through on other occasions may be called a 'part' or 'routine'”. Another relevant aspect of performance is what Goffman (1959: 32) calls front, namely, "that part of the individual's performance which regularly functions in a general and fixed fashion to define the situation for those who observe the performance". Relevant aspects of front are setting (Goffman 1959: 32), in other words, assemblages of sign equipment, and personal front (Goffman 1959: 34), that is, "items that we most intimately identify with the performer himself”. Certain other conditions of these media events also coincide with Goffman's 
dramaturgical model. For instance, for the duration of the interview the participants are front stage, while anything that might be said immediately before or after it, occurs backstage (Goffman 1959: 109-140).

\subsection{Performance: participants}

Goffman's performance paradigm is not confined to individuals. He (1959: 85) points out that "in many interaction settings some of the participants cooperate together as a team or are in a position where they are dependent upon this co-operation in order to maintain a particular definition of the situation". In the attempt to delineate aspects of the performance like routine, front, and teamwork, the discourse analysis relevant to this aspect of the framework will concentrate on turntaking, topic control and evidence of collaborative work between participants. Using additional semiotic analysis, attention will also be paid to various signs involved in these interactions, especially in the construction of aspects of front like setting and personal front.

\subsection{Participation framework: audience}

In his work on performance, Goffman naturally includes the concept of audience. However, it was in his essay "Footing" (1981: 124-157) that he factored audience into the concept of participation framework in a way that has become influential in the analysis of media discourse. In Goffman's (1981: 3) view, “when a word is spoken, all those who happen to be in perceptual range of an event will have some sort of participation status relative to it. The codification of these various positions and the normative specification of appropriate conduct within each provide an essential background for interaction analysis”. O’Keefe (2006: 374) summarizes the typical media participation framework as follows:

This is a three-fold construct inclusive of an audience as a participant in the interaction since the talk that unfolds from moment to moment in a media interview is aimed not just at the interviewer who has asked the questions, or the interviewee who is being asked the question, it is shaped for and by the audience who watch or listen to that show in that social context.

Goffman (1981: 137) specifies that "an utterance does not carve up the world into precisely two parts, recipients and non-recipients, but rather opens up an array of structurally differentiated possibilities, establishing the participation framework in which the speaker will be guiding his delivery”. The main distinction he makes as regards recipients of the delivery concerns hearer status: on one hand, he sees some hearers as non-ratified participants who, for example, inadvertently or otherwise overhear an interaction; on the other, ratified participants are those who in some way have a recognised status within the participation framework, although this may be very fluid. As Goffman (1981: 131) states, "a ratified participant may not be listening and someone listening may not be a ratified participant”. O’Keefe (2006: 18) neatly sums up the implications of these insights for media discourse analysis:

\footnotetext{
Goffman's notions of ratified and unratified hearers can be applied to say that everyone who watches/ listens to a television or radio programme is a ratified hearer. They are part of the discourse event and may join in if they choose [...]. This model allows us to promote the audience to official hearer status within the event. The audience is no longer an overhearer of talk on television or radio; they have a place within the participation framework. This provides the analyst with a mandate to examine how talk is modified and guided by studio participants (e.g. host and guest) to meet the demands of fullyratified hearers who are not physically present but who are out there within the participation.
}

This is of particular point, considering that many viewers of these interactions will be highly ratified by virtue of the fact that they have deliberately clicked on the interview to watch it. Of further relevance to this paper is the way in which Goffman (1981: 128) considers the implications of his insights into hearer status for speakers, particularly as regards changes in footing:

A change in footing implies a change in the alignment we take up to ourselves and the others present as expressed in the way we manage the production or reception of an utterance. A change in our foo- 
ting is another way of talking about a change in our frame for events [...] participants in the course of their speaking constantly change their footing, these changes being a constant feature of natural talk.

Fairclough (1995: 127) notes that "a single participant may have a complex identity in the sense that s/he may individually be having to negotiate a number of activities successfully or simultaneously within a programme, involving perhaps the sort of changes in 'footing' described by Goffman.” The media discourse analysis relative to this aspect of the framework will focus particularly on the linguistic features entailed in the construction of identity and relations simultaneously, particularly modality and deixis.

\subsection{Face: institutionalized attributes of the manager}

Goffman's (1967) insights into the performance aspect of interaction also overlap with his concept of face. Therefore, a consideration of face and facework completes the theoretical framework. Goffman (1967: 5) defines face as "an image of self delineated in terms of approved social attributes". Goffman (1967: 5) alternatively defines it as "the line others assume [an interactant] has taken during a particular contact". He (1967: 7) further specifies that "the line maintained by and for a person during contact with others tends to be of a legitimized institutionalised kind". The approved institutionalised attributes of a football manager are intertwined with his professional ones, i.e. his tactical expertise, his powers of man management, his abilities as a motivator, all of which should ideally ensure his ability to win. Although Goffman (1967: 12) maintains that "ordinarily the maintenance of face is a condition of interaction, not its objective", the potential for calling the attributes that are part of a manager's face into question is greater in defeat than following a draw or victory. As Wagg (2007: 454) observes, "Football managers are experts one minute. The next minute they're fools: we, the ordinary people could do better". Goffman (1967: 10) states that face is "on loan [...] from society" in the sense that it can be withdrawn unless an individual "conducts himself in a way that is worthy of it". The defeat scenario offers more opportunities for calling in that loan, because aspects of the pursuit and maintenance of face like "solving problems and performing tasks" (Goffman 1967: 12) are open to challenge.

\subsection{Facework}

Logically, the interaction participant most likely to threaten the manager's face is the interviewer, whose own institutionalised face presumably includes not only sympathising with defeated managers, but also questioning their tactics and enquiring about what went wrong. Thus there are two faces at stake in these interactions. The question is to what extent, if at all, the interviewer calls in the loan, and how far managers are prepared to extend credit to interviewers.

Goffman (1967: 12) regards reciprocal face-saving as "the traffic rules of interaction", that is, a system based on reciprocal self-respect and consideration in social encounters that is meant to maintain one's own and others' face. The final part of the analysis will consider how the performance aspects of these media interactions are characterized by particular forms of facework, in other words, by "the actions taken by a person to make whatever he is doing consistent with face" (Goffman 1967: 12). The relevant media discourse analysis will focus mainly on modality. In defining the ritual game (Goffman 1967: 31) entailed in facework in these interactions, reference will also be made again to what Fairclough (1995: 128) calls interactional control features, particularly control of topic.

\subsection{Face, habitus and 'politic behaviour'}

Although some linguistic aspects of these interactions appear to constitute face threatening acts (FTAs), the participants continue to behave as if they did not. The interviewers' turns are comprised of a number of bald on-record declarations, declarative questions and wh-questions, as well as intrusive epistemic modality, all of which appear to constitute face threatening acts. For their part, the interviewees appear to make more frequent use of the kinds of non-propositional dis- 
course markers conventionally regarded as forms of polite hedging. Similarly, it is the interviewees who employ inclusive personal pronouns, a form of politeness associated with positive facework and the establishment of commonality. This asymmetrical distribution of facework appears to run contrary to the power relations of the interactants involved. Yet, this imbalance does not appear to indicate negative facework on the part of the interviewer; nor does the managers' 'failure' to answer the journalists' questions appear to threaten the latter's professional face.

Watts (2003) uses the term "politic", as distinct from "polite", to cover usages that are not strictly expressions of linguistic politeness and therefore not impolite given the context and the habitus (Bordieu 1977). Watts (2003: 147) defines habitus as "the set of dispositions to behave in a manner which is appropriate to the social structures objectified by an individual through his/her experience of social interaction”. Politic language and behaviour can take the form of linguistic impoliteness when this is expectable in terms of the objectified sense of the interaction derived from the habitus. In other words, "the linguistic structures that realise facework strategies are by no means always associated with linguistic politeness" (Watts 2003: 89). Consequently the final part of the analysis of face in these interactions will draw on Watts' study of politic behaviour and on his references to Bourdieu's concept of habitus.

\section{Data selection criteria}

The article will concentrate on post-match interviews with defeated managers, because the analytical model outlined above ought, logically, to be applicable most evidently in such interactions. In the first place, it is presumably harder for managers to suppress their feelings following defeat or, on the contrary, to exploit them. Thus, it will be interesting to see what, if any, coping strategies are used to hold them in check. Additionally, it will also be interesting to see how the interviewer 'handles' his interviewee in such situations, and define what kind of performance interviewee and interviewer jointly put on.

Only one team can win the championship. However, modern football is organized in such a way as to offer ample opportunities for 'weaker' teams to achieve a measure of success by qualifying for domestic cup competitions, or for runners-up to qualify for the even more lucrative and prestigious international tournaments like the Europa League and the Champions League. A single defeat can often end a team's prospects of finishing high enough in the table to enter the European competitions, or of even staying in the Premier League itself, and thus continuing to enjoy the financial rewards this apparently brings. However, even if a defeat is not decisive, it is often seen as affecting a team's chance of ultimately qualifying for Europe or avoiding relegation. Managers presumably know that post-match interviews on the heels of defeat will be scrutinised, particularly by the online fan base. Lastly, a single defeat can lead to the termination of a manager's contract; in a sense every defeat is a step nearer that conclusion, which is one that affects all but a select group of managers. In such media interactions, then, the issue of face would appear to be particularly acute, both because the need to maintain "the positive social value a person effectively claims for himself” (Goffman 1967: 5) is more clearly at stake, and because the obligation to be considerate on the part of the journalist is proportionally greater.

\section{Findings}

The following section will examine turn-taking and will apply close linguistic analysis to the transcripts of two post-defeat interviews with managers whose teams narrowly lost to Manchester United during the 2008-2009 season. The first is a post-match interview with Steve Bruce, manager of Wigan Athletic, beaten by Manchester United on May 13, 2009; the second is with Martin O'Neill following Aston Villa's defeat at the hands of the same team on April 5, 2009 (see Appendix 1 for full transcripts). 


\subsection{Generic conventions}

The basic conventions of the post-match interview have remained stable in the transition from traditional medium to online versions. The interaction can last up to four minutes. The managers are never interviewed together. The interviews are conducted soon after the match, once the manager has emerged from the dugout or dressing room. What Goffman (1959: 32) defines as the setting is also significant. An important prop is the display board bearing the logos of the television company, the team and the Premier League sponsors. It is an unmistakable corporate frame and one within which managers' words must be assessed, because it adds a further range of tensions and responsibilities for both the interviewer and the interviewee. Wagg (2007: 446) makes these implications very clear:

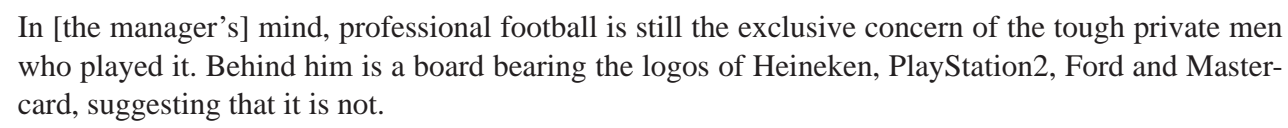

In Goffman's (1959: 85) terms, certain of the performers and audiences (the interviewee, the interviewer, together with technicians) combine to act as a 'team' to put on a performance for the benefit of the remaining overhearing audience. In this part of the analysis, we will be concentrating on the two major performers in the event, namely the manager and the interviewer.

\subsection{Turn-taking and topic control: turn 1}

A glance at both transcripts (see Appendix 1) reveals a striking resemblance in their interactional control features. Each interview is comprised of three turns for each participant, and in both interviews the managers' turns are far longer than the interviewers'. In each case, the interviewer's opening turn is formulated as a declarative question:

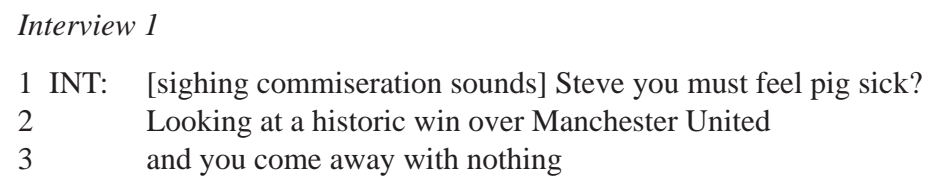

1 INT: Martin that must feel like a real kick in the teeth?

At the level of topic control, the interviewers appear to be inviting the interviewees to express their feelings about the result, and in fact each of them complies with that pragmatic implication:

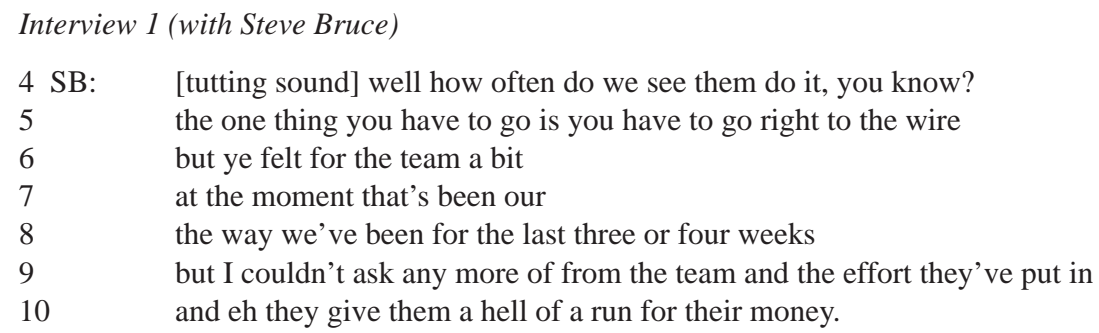

In interview 1, Steve Bruce expresses a gamut of emotions: frustration mingled with admiration for his opponents, compassion for the team after this narrow defeat, rueful acceptance that teams can go through patches like this despite playing well. He closes the turn with the expressive idiom "gave them a hell of a run for their money", which conveys satisfaction with how the team played, if not with the result, something that emerges as a constant in both interviews. Martin O'Neill's responding move respects the topic control in a similar way. 
Interview 2 (with Martin O’Neill)

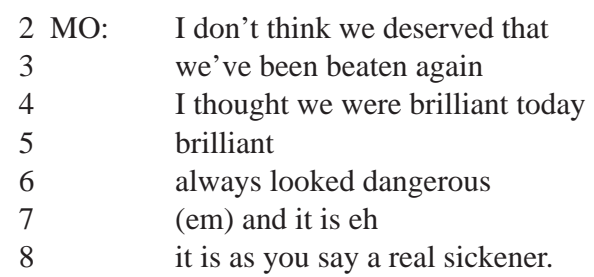

Although he uses the mental process verb think at the beginning of his turn, in pragmatic terms, the first instance would seem interchangeable with the mental process verb feel and, therefore, can be taken as complying with the topic control initiated by the interviewer. The fact that he closes his turn by returning to the interviewer's initial point and agreeing with it is a clear instance of compliance. However, the length of the turn also means that each manager does somewhat more than merely comply with the topic: each seizes the opportunity to praise his team's performance, quality of play and, in the case of Bruce, its unparalleled commitment and effort. Thus, the initial statements and declarative questions leave each manager considerable scope to respond more indirectly than would be the case with a yes-no, what-who question, and this allows them to foreground aspects of the topic that aren't really anticipated in the interviewers' opening turns, without, however, supplying a clear dispreferred response.

\subsection{Topic control: turn 2}

The second set of turns follows a broadly similar pattern, with the managers responding at greater length, partly complying with the topic control, but not without digressing to list positives. In interview 1 , the second adjacency pair is initiated by a question: "How many other teams have you seen push the champions that far?" (L11). Strictly speaking, Bruce does not stick to the question in his reply. Evidently he sees the illocution as being nearer a declarative with tag question, like "you almost won the game, didn't you?", and this is shown by the close of his turn: "with eh a little bit more luck, then it might have been our night" (L19). Once again, Bruce takes the opportunity to stress the "honesty and integrity" (L17) of the team's effort.

The second adjacency pair in interview 2 is initiated by a more specific question about tactical decisions: "Did you adjust your thinking when you realised that Garry Neville was playing centre back?" (L10). After a brief hesitation, O’Neill almost brushes aside this question with "not particularly" (L 12). He then makes a short-lived show of taking the question seriously by talking briefly about Garry Neville, before he abandons this mid-sentence and brusquely switches topic, flouting the topic control signalled by the interviewer's very specific question:

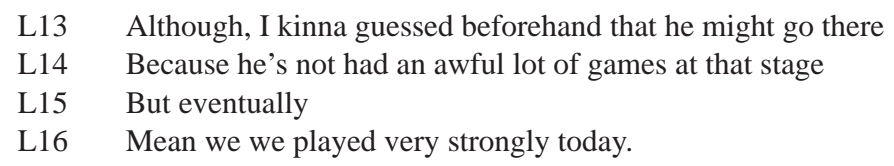

The main body of his turn is devoted to mentioning the strength of his team's performance, the absence of key players, the quality of the game as a whole, and the undeserved nature of the defeat. Significantly, when he is talking on these issues, his discourse is marked by intensifiers like the adjectives "incredible" and "fantastic", or the repeated adverbial phrases "really really" (L22); it also features marked structures like a demonstrative followed by a pseudo cleft - "and that's what it was” (L 21), and even a quasi parallelism: “we've been beaten and we didn't deserve to be beaten”. (LL 23-24). By contrast, when he is replying to the interviewer's direct question, he makes wider use of hedges: "not particularly” (L12), "kinna” (L13) "not had an awful lot” (L14), all in close succession. Such variations suggest different levels of commitment to the "official' topic of this adjacency pair, the one broached by the interviewer, and the 'unofficial' one, to which most of his turn is really devoted. 


\subsection{Topic control: turn 3}

The third and final turns in each interview once more see topic control passing from interviewer to interviewee. The last question put to Steve Bruce is: "when you can put on a performance like that is it a case now you know in the summer of working hard to see what you can add?" (LL 2021). Bruce deflects this closed question with "well, of course, we're always looking to add you know" (L 22), an answer in which of course deftly signals agreement and always suggests that it is quite possibly superfluous, if not irrelevant. Bruce, conceivably hypersensitive to the pragmatics of the question, appears to interpret it as a comment on his decision to field an inexperienced player, and the rest of the turn is spent, not answering the question, but defending his decision and praising the player's performance.

Ironically, the last and shortest question in the interview with O’Neill, "What changed?” (L25), elicits the longest 'reply'. In his lead-up to an 'answer', O'Neill' reminds listeners that "we're two-one ahead" (L 28) and that "maybe we should've been further ahead" (L29); he mentions "great chances" (L30) and that "we'd always the chance to go three-one in front" (36). After this sequence of 'highlights', O'Neill does say that the turning point was a foul that was not given against Manchester United in the build-up to their winning goal, although he does not criticise the referee openly or even mention him. However, having answered the question, he immediately wrests the topic back and proceeds with a glowing tribute to his team. He finishes by looking forward to the next match with a confidence based on today's performance. This possibly indicates a strategy that whenever managers feel they are about to criticise others (referees, opponents, their own team) they switch to a more positive line, like praising team performance.

These examples appear to confirm Beard's (1998: 65) description of the turn-taking system in post-match interviews: "One notable feature of these interviews is that they seem to involve very few questions; after a fairly general question has been asked, the managers take their cue to speak at length". The analysis of topic control suggests that irrespective of the question type, manager interviewees devote proportionally more time to not answering the questions than they do to answering them, in the course of which 'evasive action' they are highly likely to defend their own decisions, praise their team's commitment and skill, their contribution to an entertaining game. They may also refer to questionable decisions, though without naming the referee.

Nevertheless, there is no fighting over topics. This means that the turn-taking etiquette can be observed scrupulously in these interactions. There are no interruptions, or overlaps, and the managers' use of fillers and repetitions further ensures that none occur. There are not even audible signs of back channels like hm, right, yes from the off-screen interviewer, though these presumably are conveyed by facial expression and through kinesics. The interviewer does not control the interaction by insisting on answers to the few closed questions he poses; rather he shapes it through statements or open questions that allow the interviewed manager considerable scope for topic control. Therefore, these interactions are highly collaborative; the questions, which might best be described as cues, and the repeated turn-taking pattern appearing to provide the basic outline of stabilized media routine, in which nothing of real moment is actually said.

\subsection{Expression of feeling}

Although Beard (1998: 65) identifies suppression of feelings as one of the greatest difficulties faced by managers during such interviews, the extracts analysed so far indicate that, on the contrary, each manager readily expresses feelings of disappointment, injustice, frustration and optimism in these interactions in the course of their respective turns. This is most obvious in the initial adjacency pair in each interview, each beginning with an opening assumption about how the manager is feeling. Bruce employs the paralinguistic tut (L4) to convey this. He also uses the verb “felt” in his first answer. O'Neill's concession that it is a "sickener”(L8), underlines the emotional impact of the result. Additionally, his use of the mental process "think" is expressed so pointedly and forcefully that, in pragmatic terms, its illocutionary impact is closer to feel. Viewed from 
the point of view of Hallydayan Functional Grammar, in such utterances, each manager presents himself, and also others within the deictic frame of reference, not so much as Actors but primarily as Sensers who have an emotional stake in the outcome (see e.g., Bloor/Bloor 2004: 111-120).

The feelings revealed in these post-match interviews may not be vented quite so openly as they are with the players and other club staff on the touchline, in the tunnel or in the dressing room; nevertheless, it is possible that they are useful for conveying the impression that the manager identifies emotionally with the team. This suggests that impressions of spontaneous emotion may also be useful in consolidating the manager's rapport with the fan base, indicating that he, like them, feels the sting of defeat, and that he is part of the we that they comprise. An explanation for managers' willingness to express certain feelings might be found in the impermanence that, apart from a few celebrated cases, now characterizes the job. In modern football, today's team manager may very well be tomorrow's opposing one; expressing emotional empathy with today's team, no matter how short-lived the manager's eventual tenure, may have emerged as a convenient strategy for displaying loyalty and commitment.

\section{Participation framework}

The participation framework in these media events includes the interviewee (the manager) the participating interviewer and what Goffman (1981: 133) describes as the encircling hearers, presumably including other journalists and technical staff. We complete the framework by bringing into the picture Goffman's (1981: 138) absent but imagined recipients, possibly including the players, club chairman or owner, sponsors, shareholders - in some clubs - and certainly numbering members of the fan base, all more or less ratified participants.

\subsection{Deixis}

The turn-taking system also gives the manager unimpeded access to the overhearing audience. Certainly both managers interviewed seize the opportunity to redress the impression made on the audience(s) by the stain of defeat. Besides stressing the quality of the performance and the harshness of the outcome, one significant way managers do this is through the deictics employed in the course of the interview.

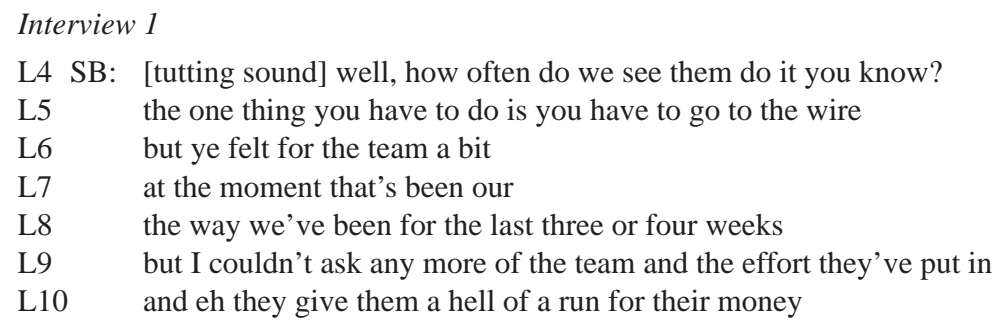

Fairclough (1995: 139) notes that, in media discourse, "slippage” between exclusive and inclusive pronouns is a fairly common occurrence. Bruce's use of the pronouns you and we is a case in point. In the above excerpt it is not certain that either "you" or the demotic "ye" is addressed exclusively to the interviewer. On L4 "you" might be addressed to the interviewer, though it could equally include the audience. In the two occurrences on L5, however, it appears to refer to any team playing Manchester United. The use of "ye" in L6 is surprising in that one would expect $I$ to be used as the subject for such a subjective verb. Whether or not this slippage is intentional, it effectively expresses the assumption that all the overhearing audiences feel compassion, rather than more negative feelings, for the team.

The use of we is equally shifting. On L4 it is inclusive of interviewer, manager, players and audiences. It means that grabbing a last minute winner is something that everybody knows Manchester United do regularly, and it appeals to a generalised recognition of this fact as an attenuating circumstance. Elsewhere in the excerpt, we is used exclusively, when the manager assumes 
team identity, which it is important for him to do. No matter how short-lived a manager's tenure, he must be seen to identify naturally with the team, which is the unchanging core product that appeals to the consumption community of the fan base. The other pro-forms used are $I$, they and them. Considering this is an interview, it is interesting to note that $I$ is used only three times in the entire interaction and only once in this excerpt, when Bruce wants to give his professional opinion of his team's performance. When Bruce does assume full managerial identity, they is used twice to denote his team, Wigan F.C. Them is used twice to refer to the opposing team, significantly as objects rather than subjects, as befits an opposition.

Interview 2 shows show a more sustained use of deixis to reinforce team identity through a them-us opposition, reflected in the way O'Neill's use of the exclusive we (4 instances) to refer to his team (in which he includes himself) is matched by they (4 instances) to refer to the opposition:

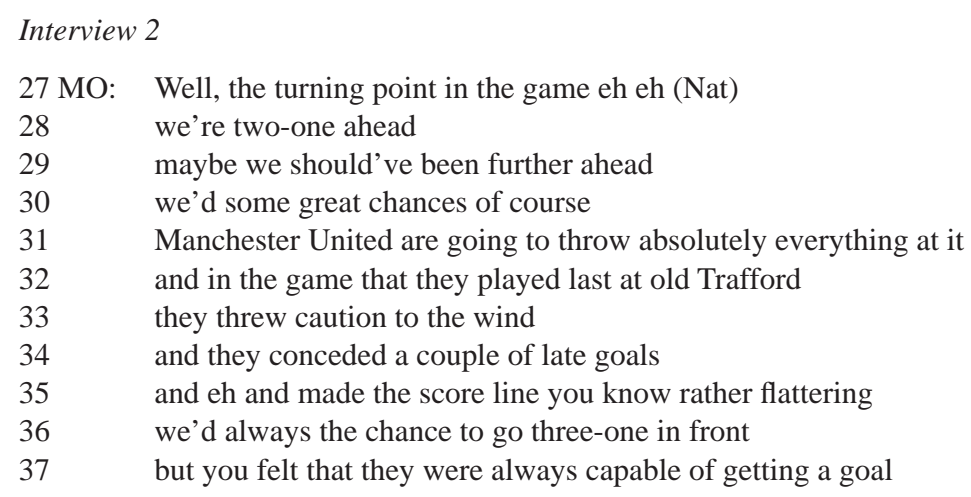

What is more, slippage of footing possibly occurs here, in that we is habitually how fans refer to their team, and it is not difficult to imagine the fan base feeling that the manager's use of that pronoun coincides with their own. The inclusive you is used with the verb "felt", though the pragmatics of the word would seem to reveal some kind of managerial hunch or technical judgement. If that is so, the use of you is significant, showing that the manager somehow distances himself from a personal conviction that would undermine the sense of club identity conveyed by we. Both Bruce and O'Neill use the inclusive you/ye in a way that would seem to indicate sensitivity to the feasible expectations of the imagined recipients.

Each manager exploits deixis for a number of purposes. The opposition between we and they and us and them possibly works to shore up any wavering loyalty among the supporters by highlighting the antagonism upon which supporter/consumer loyalty is based. Inclusive pronouns also play an important role in this strategy. The use of the inclusive you not only establishes commonality with the interviewer, it is also useful in appeals to the larger audience, a linguistic device that may help bring them back 'onside', so to speak. Further, the recurrent use of the inclusive we may strengthen ties between the team and manager, and also help reinforce the bond between club and fanship, in pursuit of the kind of 'consent' that allows the club to continue to exert brand appeal.

\section{Face}

The turn-taking system (analysed in sections 7.2.-7.4.) also furthers understanding of the patterns of facework in both interactions. As was pointed out in section 5.5., Goffman sees reciprocal facesaving as the rule in social interactions, and regards facework as the "traffic rules" that structure them. The current section sets out to trace the 'highway code' of face in these media interactions, in other words, to define the resources the interviewer and interviewee draw on to maintain reciprocal face and the reasons for doing so. 


\subsection{The threat to managers' face}

It has been suggested in section 6 that face is an issue in post-match interviews following defeats, because it is then that the manager is potentially most open to criticism and face-threats. These may not just come in the form of chants from disenchanted fans on the terraces, but increasingly from e-mails, tweets, and text messages sent by fans and inserted into the match report the streamed interview is embedded in. After a defeat these are often critical of the manager, to say the least, and some explicitly call for dismissal. In this scenario, it is reasonable to expect the journalist to ask pointed questions about tactics, team selection, and the like. This may also entail the risk of retaliatory face threats on the part of the interviewee.

\subsection{Reciprocal facework}

The initial turns are remarkably similar and both seem the most interesting from the point of view of reciprocal facework. In terms of maintaining their own face as hard-bitten professionals at ease in the harsh world of Premier League football, both interviewers display considerable familiarity with the interviewees. Each interview begins with bald on-record assumptions about the manager's feelings:

Interview 1

1 INT: Steve you must feel pig sick

Interview 2

1 INT: Martin that must feel like a real kick in the teeth

The epistemic modality used in both utterances could be construed as intrusive and hence constitute a potential face threat. However, their force is mitigated by the rapport-building use of the manager's first name and by the clear pragmatic implication of sympathy and consideration for his feelings. The managers' responding moves feature supportive responses. Steve Bruce's use of the inclusive we - possibly suggestive of "we who work in Mediasport" - quickly establishes commonality with the interviewer and is sustained throughout the interview with protracted use of inclusive pronouns. Martin O’Neill's response is essentially an acknowledgement meaning: “yes you're right", clinched by agreement: "it is as you say a real sickener".

Throughout these interviews, each manager displays considerable expertise in considerate protective manoeuvres (Goffman: 1967: 16). They countenance the professional behaviour of the interviewer; they do not take offence; their responses are minimally compliant; they acknowledge interviewers' sympathy; they concur and establish commonality through specific verbal acts that accord credence to the interviewer's observations. In due payment for this, they are conceded lengthy turns and considerable scope for expressive evaluations of events (what might have been) and projections like I think; they are given ample opportunities for indirect protective manoeuvres (professions of team loyalty and admiration for players); they are allowed to make points about quality of performance, skill, reliability, and commitment to improvement. Both start from a position of vulnerable face, but the collaborative nature of the interaction allows each manager to keep it.

On the other hand, as the analysis of the turn taking system in sections 7.2.-7.4. has suggested, the longer the interview goes on, the less time the managers actually spend answering the interviewers' questions. At most they provide token answers that are embedded in discourse which is largely devoted to bolstering their face and their team's by drawing attention to aspects of the team performance that reflect well on their professional standing, allowing each manager to bathe, as it were, in reflected glory of his own making. Despite this asymmetry, the interviewers do not appear to detect any threat to their own professional face. On the contrary, the interviewer does not become impatient if the interviewee does not answer his questions; he does not bully or hec- 
tor the interviewee, as often occurs in political interviews, he waits patiently and sympathetically while the manager holds the floor.

\subsection{Politic behaviour and habitus}

These media interactions would appear to confirm Watts' (2003: 89) contention that "the linguistic structures that realise facework strategies are by no means always associated with linguistic politeness". Neither the journalists' more pointed questions, nor the managers' ability to wriggle out of answering them, appear to involve any reciprocal awkwardness, or convey the impression that their respective linguistic strategies are construed as face-threatening. The turn-taking system in these interactions entails language usage that may at certain points flout traditional parameters of politeness, but there appear to be no serious implications for face: for interviewers the habitus can entail being intrusive and familiar, while for the manager it may involve being evasive and not relinquishing the floor before he is ready to. In Watts' terms these kinds of deviations are expectable, involve no threat to face, and as a consequence they are "politic" behaviour in operation in the social activity. They are, in other words part of social practice (2003: 80). At the same time, the fact that the habitus does not presuppose "a conscious aiming at ends or an express mastery of the operations necessary to attain them" (Bourdieu 1977: 72) means that the interactions appear natural and spontaneous, or as Bourdieu (1977: 72) elegantly puts it: "collectively orchestrated without being the orchestrated action of a conductor".

\subsection{Face and simulacra}

In the final analysis, then, face ultimately resides in the participants' ability to act as co-performers in this media genre: the managers as disappointed but undaunted by defeat, the journalists as supporting actors who know how to feed the right questions and simulate interviewers grilling hapless football managers. From here it is but a short step to the notion of simulacra advanced by Baudrillard (1993: 343), and to his point that "present day simulations try to make the real, all the real, coincide with their simulation models".

It is quite feasible that the same journalist will put similar questions to the same manager after he has taken charge of another losing team. However, those same questions will be no more face threatening than they are in these extracts. This may be so because the manager is assessed within the narrow confines of the media event and not on the basis of his track record. None of a manager's professional or personal history and 'real' experience ever emerges in the interviews. Similarly, very little 'real' information about the managers' opinions or feelings about the team, the club, or the game filters through. In such events, managers appear to exist in an eternal present of absolute commitment to and involvement with the club, and thus of ease and conviction within the media event itself. Both of these interviews are conducted with men who have since changed jobs, yet the similarities in their post-match performances indicate that their fidelity to what Baudrillard (1993: 359) calls "the decoding and orchestration rituals of the media" is likely to be more durable than their rapport with their respective clubs. The consistencies in the two interactions suggest that managers are quick to shape their post-match discourse to the media model. This ensures the job rotation can continue, while maintaining the impression of permanence and loyalty so important for endorsing the club brand. As such, these media events would appear to embody the Baudrillardian paradigm summarized by Merrin (2005: 65):

The media, therefore, industrially processes the 'raw' event into a finished consumable product, eclipsing reality in favor of that realized simulacral model given material force by the medium.

Further, managers' and journalists' joint ability to reproduce the 'raw reality' of defeat in terms of the stabilized medium model means that the media consumption product is likely to continue to effectively "impose [its] single pattern of consumption” (Merrin 2005: 65), despite the likelihood of changes taking place in the personnel of the participation framework. 


\section{Conclusion}

Beard (1998: 67) makes the point that "football managers are often singled out for ridicule for the way they speak in interviews". The two interactions analysed here suggest that as interactants they participate in a highly stabilized media genre in which the exchange is routinized in terms of turn-taking and facework. This study indicates that once he has assumed topic control, a manager will probably use it as a means to a number of ends. One will be to seize the opportunity to take away a number of positives from a defeat, like effort, ability, and determination to do better; another will be to exploit deixis, particularly inclusive pronouns, to secure commonality by stressing team identity and assimilating the audience into this process. Further, the analysis indicates the manager is unlikely to conceal feelings like disappointment or compassion, because these may allow him to convey his identification with the team and establish an emotional common ground with the fan base. At the same time, the interviewer is unlikely to ask probing questions, and any mild face threats are basically a veneer lending credibility to this professional institutionalized face. On the evidence of the data examined here, namely, post-match interviews following narrow and 'undeserved' defeat, these mediated interactions are only apparently impromptu utterances and spontaneous natural speech acts. Instead, the consistencies in the two interviews, held on different occasions and involving different participants, appear to indicate that they are virtually semi-scripted and structured interactions at which managers have become adept, through practice, at taking away a substantial number of positives, at saving their own face, their team's, and their club's, while allowing the interviewer to preserve his.

The analysis also suggests that defeated managers' post-match interviews work on the consumption community of the fan base at a more general level. Through their words football consistently emerges as a complex product. An important aspect of product satisfaction is winning, but other values and qualities are presented as part of the validity of the overall brand, embodied, in this case, by the losing team. Thus, in the defeat scenario managers emphasise added value features like entertainment, performance, commitment, effort, promise. The outcome of the match is balanced against the quality of the play (brilliant, entertaining); the present is measured against the future and against potential; the temporary setback of defeat is put in the scales against determination to improve the product, the essential validity of which is undermined by an imponderables like bad luck.

Wenner/Gantz (1989: 242) note that it is the tension between reality and uncertainty in sport that gives its viewing a unique flavour and appeal (see also Gratton/Solberg 2007: 11). When losing managers emphasise the unpredictability and the injustice of a defeat, they are also stressing this uncertainty principle and hence one of the strongest selling points of team sport as a whole. Therefore they are implicitly providing cogent reasons to the participating audience for continued consumption of it, irrespective of the result. It is as if they were reassuring the fan base, as Martin O'Neill seems to be doing at the end of his interview, that there is still "all to play for" (L 66) and, by implication, all to watch for and, thereby, consume for. Wagg (2007: 432) believes that "football culture generated the myth of the football manager because it suited the interests of all interested parties: administrators, club proprietors, the football media, players, ex-players and aspiring technocrats". This may explain the wider dynamics underpinning the post-match interview as a stabilized genre; it may also account for certain of the specific coping strategies that managers, for all their differences, appear to share, when facing the media and the 'cyber-tribe' in streamed post-match interviews following defeat.

\section{References}

Armstrong, Garry/Mitchell, Jon 2008: Global and Local Football: politics and Europeanisation on the fringes of the EU. Abingdon/New York: Routledge,1000-1939.

Baudrillard, Jean 1993: The Precession of Simulacra. In Natoli, J./Hutcheon, L. (eds.), A Post-Modern Reader. Albany: State University of New York Press, 342-375.

Beard, Adrian 1998: The Language of Sport. London: Routledge. 
Beck, Peter 1999: Scoring for Britain: international football and international politics. London: Frank Cass Publishers.

Bellamy, Robert 1989: Professional Sports Organizations: Media Strategies. In Wenner, L. A. (ed.), Media, Sports, and Society. Newbury Park: Sage Publications, 120-133.

Bloor, Thomas/Bloor, Meriel 1995 [2004 edition]: The Functional Analysis of English. London: Hodder Arnold.

Bourdieu, Pierre 1977: Outline of a Theory of Practice. Cambridge: Cambridge University Press.

Fairclough, Norman 1989 [2001 edition]: Language and Power. London: Longman.

Fairclough, Norman 1995: Media Discourse. London: Arnold.

Giulianotti, Richard 1999 [2004 edition]: Football: A sociology of the global game. Cambridge: Polity Press.

Goffman, Erving 1959 [1990 edition]: The Presentation of Self in Everyday Life. London: Penguin Books.

Goffman, Erving 1967 [2008 edition]: Interaction Ritual. New Brunswick: Transaction Publishers.

Goffman, Erving 1981: Forms of Talk. Philadelphia: University of Pennsylvania Press.

Gratton, Chris/Solberg, Harry Arne 2007: The Economics of Sports Broadcasting. Abingdon: Routledge.

Mahan, Joseph/McDaniel, Stephen 2006: The New Online Arena: Sport, Marketing and Media Converge in Cyberspace. In Raney, Arthur/Bryant, Jennings. (eds.), Handbook of Sports Media. New Jersey: LEA, 409-431.

Merrin, William 2005: Baudrillard and the Media. Cambridge: Polity Press.

O’Keefe, Anne 2006: Investigating Media Discourse. Abingdon/New York: Routledge.

Real, Michael 2006: Sports Online: the Newest Player in Mediasport. In Raney, Arthur/Bryant, Jennings (eds.), Handbook of Sports Media. New Jersey: LEA, 171-184.

Real, Michael 1998: MediaSport: Technology and the Commodification of Postmodern Sport. In Wenner, Lawrence (ed.), Mediasport. London: Routledge, 14-26.

Smith, Adrian/Porter, Dilwyn (eds.) 2004: Sport and National Identity in the Post-War World. London/New York: Routledge.

Wagg, Stephen 2007: Angels of us all? Football Management, Globalization and the Politics of Celebrity. In Soccer \& Society, 8:4. London: Routledge, 440-458.

Wagg, Stephen (ed.) 2004: Football and Social Exclusion. Abingdon/New York: Routledge.

Watts, Richard 2003: Politeness. Cambridge/New York: Cambridge University Press.

Wenner, Lawrence 1998: Preface In Wenner, Lawrence A. (ed.), Mediasport. London: Routledge, xiii-xiv.

Wenner, Lawrence/Gantz, Walter 1989: The Audience Experience with Sports on Television. In Wenner, Lawrence (ed.), Media, Sports and Society. Newbury Park: Sage Publications, 241-269.

Wilkinson, Jeffrey 2006: Streaming Media. In Grant, August/Meadows, Jennifer (eds.), Communication Technology Update. Burlington MA: Elsevier Inc, 126-138.

Whitsun, David 1998: Circuits of Promotion: Marketing and the Globalisation of Sport. In Wenner, Lawrence (ed.), Mediasport. London: Routledge, 57-72.

\section{Web pages}

Bruce, S. Streamed interview [online]. http://www.youtube.com/watch?v=UUyqPz-EHCo (accessed 25 September 2009).

Jones, Dan 2009: Foreword. In Ashton Jones et al, Deloitte Annual Review of Football Finance 2009. Manchester: Sports Business Group at Deloitte, 1-3 [online]. http://www.deloitte.com/view/en_CL/cl/industries/article/2f5f8dc0 39f93210VgnVCM100000ba42f00aRCRD.htm (accessed 2 May 2011).

Jones, Ken 1996: Time after Time on Television you see players struggling to articulate and managers suppressing their innermost feelings [online]. http://www.independent.co.uk/sport/time-after-time-on-television-you-see-playersstruggling-to-articulate-and-managers-suppressing-their-innermost-feelings-1321688.html (accessed 2 May 2011).

O’Neill, Martin. Streamed interview [online]. http://www.youtube.com/watch?v=cqBJflGarw (accessed 25 Sptember 2009).

Ronay, Barney 2009: “The Manager: made in Arsenal” [online]. http://www.guardian.co.uk/football/video/2009/ aug/12/the-manager-barney-ronay (accessed 2 May 2011). 


\section{Appendix 1}

The following transcription conventions have been used: Paralinguistic features are expressed in square brackets; the transcribers best guess at an unclear utterance is indicated by brackets; a ? indicates a rising or question intonation. Fillers and repetitions have eliminated pauses in these interactions, so no transcription pauses are used. Similarly, the turn-taking system ensures there are no overlaps, dispensing with the need conventional signs for simultaneous speech.

\section{Interview 1 with Steve Bruce}

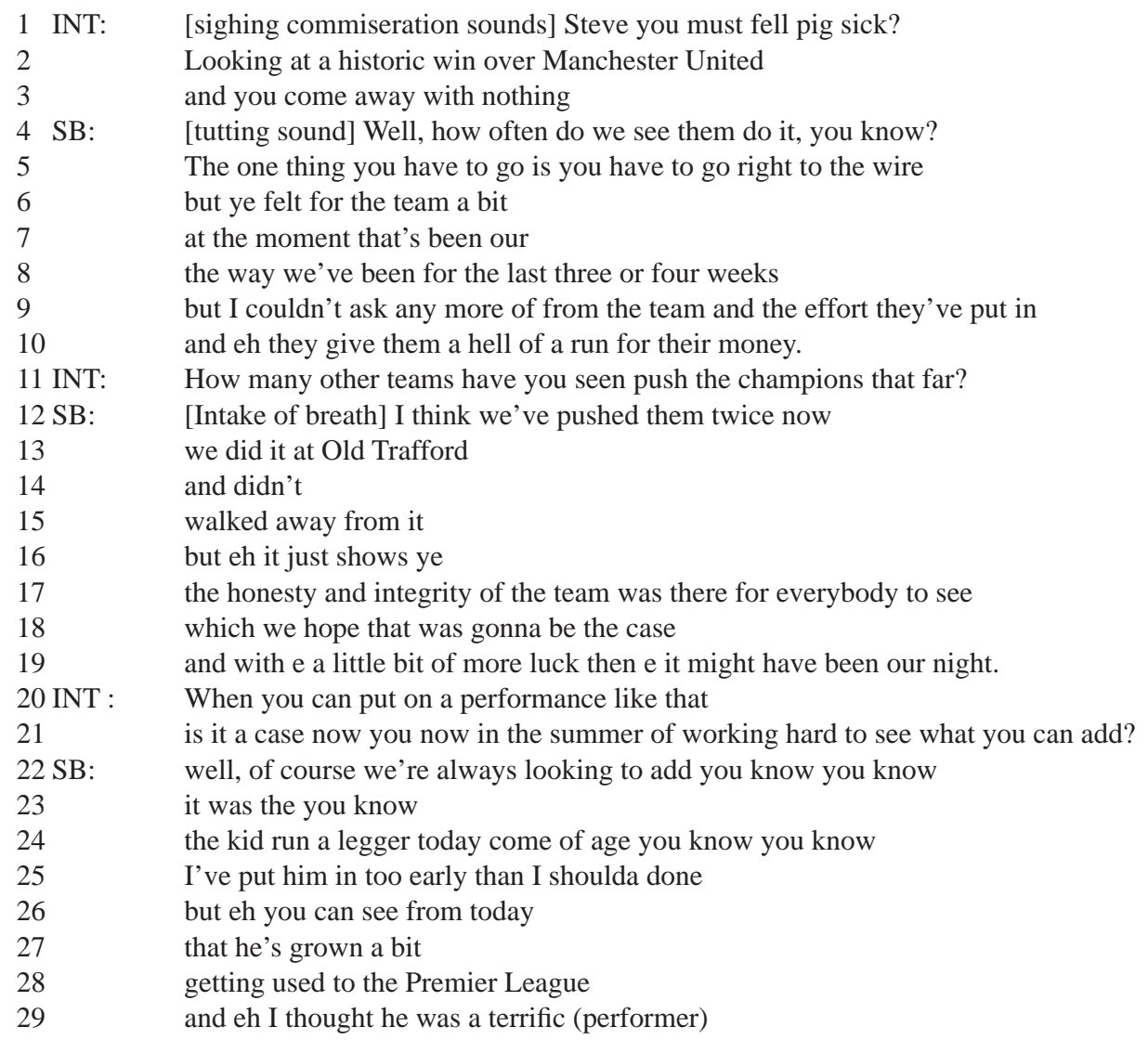

\section{Interview 2 with Martin O’Neill}

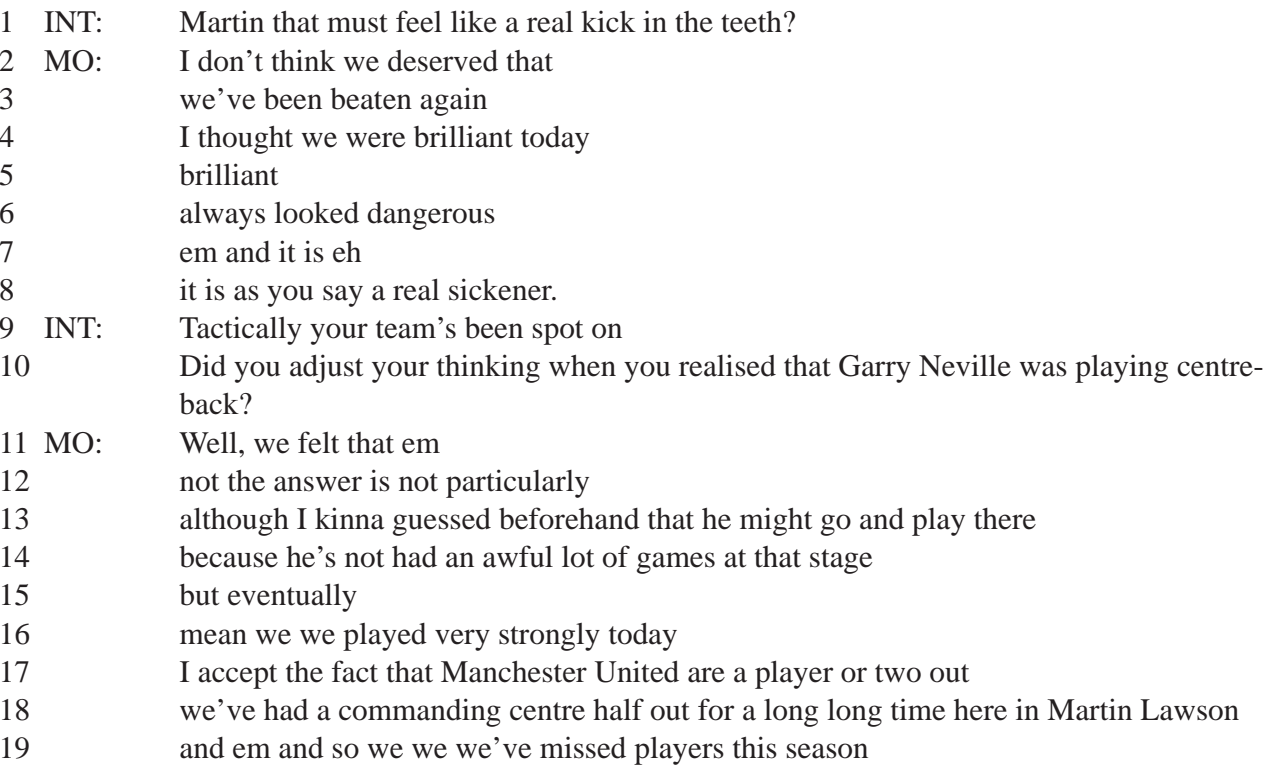


It's all very well being involved in another fantastic game

eh and that's what it was

really really incredible game

but we've been beaten

and we didn't deserve to be beaten

What changed?

What was the turning point do you think?

Well, the turning point in the game eh eh (Nat)

we're two-one ahead

maybe we should've been further ahead

we'd some great chances of course

Manchester United are going to throw absolutely everything at it and in the game that they played last at old Trafford

they threw caution to the wind

and they conceded a couple of late goals

and eh and made the score line you know rather flattering

we'd always the chance to go three-one in front

but you felt that they were always capable of getting a goal

having said that

I eh I mean it

I see the last the build up to the last em

the build up to the their final goal looks an obvious foul on Ashley Young em the corner ye I mean

that sounds as if I'm bleating em

and and I've I've em seen my counterparts go on TV and say the same thing about that and overall it's not the point,

but it em

I'll tell you what

if it'd been the other way round

it would've been a

it would've been it would have been a p

it would've been a foul

it would have been given as a foul.

however we've played splendidly in the game

we've conceded a late winner

and eh we have to well eh em

I was goin say we have to pull ourselves together

I thought we were terrific today

and that and the performance in itself will give us great heart

to go into the end of the season

we're far from finished

I know I accept the fact that the top four sides are really good sides

for every reason under the sun

we're tryin to break into that there

an we're gonna keep it going

we gotta a massive game coming up next which we have to win

Everton will feel exactly the same of course and all to play for. 